\title{
The Use of Software Systems for Visualized Treatment Objectives in Orthognatic Surgery
}

\author{
Zafer Ozgur Pektas, Beyza Hancioglu Kircelli and Ulkem Cilasun \\ Baskent University \\ Turkiye
}

\section{Introduction}

Maxillomandibular harmony constitutes a major component of the ideal facial aesthetics. Improvement of facial aesthetics is one of the main reasons that patients request surgical correction of dentofacial deformities. Orthognathic surgery enables the correction of dentofacial skeletal or occlusal discrepancies. The need for this type of surgery has increased recently, as more adult patients are seeking orthodontic treatment (Nattrass \& Sandy, 1995). Orthognathic surgery differs from other procedures of maxillofacial surgery procedures in a way that, the esthetic and psychosocial impact plays an important role in the patient perception of a successful treatment outcome. Therefore, a satisfying outcome of orthognathic surgery includes not only the decisive surgical technique and intermaxillary correction but also the accomplishment of the aesthetic goals that are successful to both patients and professionals (Sarver et al., 1988; Sarver \& Johnston, 1990; Proffit \& White, 1991). However, the concept of the ideal result is rather subjective and mainly determined by the consequency between the patient expectations and the actual result. Without a visual reference, it is hard for the patients to visualize the outcomes of the surgical procedures and to contribute to the treatment plan in the preoperative planning session (Turpin, 1995; Cunningham et al.1995). In this manner, visualized treatment objectives (VTO) are important predictive tools to interpret the patients' perspectives of esthetics and to give an acceptable preview of the result. Furthermore, these VTOs facilitate the communication between the treatment team and the patient as well as provide guidance to the desired result. They also determine the need for bimaxillary versus single-jaw procedures and whether adjunctive treatments including rhinoplasty, genioplasty, liposuction or augmentation are necessary.

Lateral cephalometric radiographs are commonly used to predict the surgical treatment outcomes. Visualized treatment prediction began with manual profile predictions. Tracing overlay approach or using templates are the two methods for profile prediction by pencil drawing. Tracing overlay approach involves manual repositoning of the overlaid tracings and is limited to simulate the effects of mandibular surgeries. In this method, cephalometric film is traced including all teeth with their occlusal surfaces on an acetate paper. Subsequently, the structures that will not be moved by mandibular surgery are traced over the original tracing with a new sheet of acetate paper. After sliding the overlay tracing so that the mandibular teeth can be seen in their desired postsurgical position, lower teeth and 
jaw is traced. By superimposing the overlay tracing back on the cranial base, it can be measured how far the lower incisor and chin is moved. The lower lip will move 2:3 as far. Also, soft tissue chin will move 1:1 with bone. Finally, soft tissue outline can be traced regarding to these reference ratios (Profitt \& Sarver, 2003). Besides, manual prediction method by using templates consists of cutting different parts of the acetate tracings and repositioning them over the original cephalometric tracing to simulate the surgical treatment. This method is compulsory when the maxilla will be positioned vertically and useful when major movements of the teeth must be simulated. Although templates can be used for any type of prediction, preparing them is more time-consuming rather than proceeding directly to a finished prediction tracing, as is done with the overlay method in uncomplicated mandibular surgery. With these two aforementioned methods, the predicted posttreatment soft tissue outline is drafted based on the reported changes of soft tissue/hard tissue ratios. Whatever the prediction method is, producing the predicted soft tissue outline is more of an art form than a scientific exercise (Profitt \& Sarver, 2003). Although, manual prediction methods are relatively informative to the professionals, as they presented only the "line drawing" profile of the surgical simulation and they can not provide a realistic image of the treatment results to the patients (Sinclair et al., 1995) (Fig. 1).

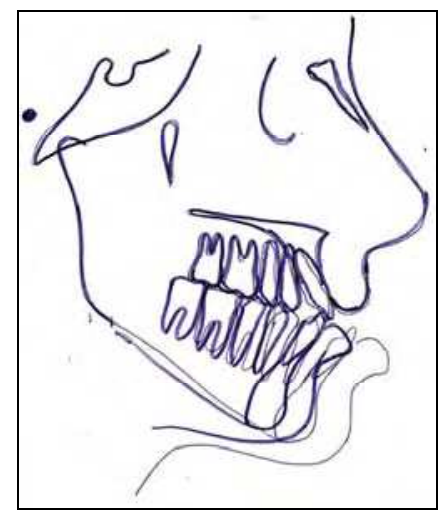

Figure 1. A manual prediction with overlay tracing method

Later on, computer-based analysis were introduced in the 1980s, where cephalometric landmarks could be digitized and the repositioning could be monitorized. This has facilitated the prediction, shortened the time and was more practical and accurate than the manual techniques (Harradine \& Birnie, 1985; Walters \& Walters, 1986). With these programs, measurements, calculations and analyses were performed by the computer. These cephalometric radiographic digitizing programs use the data from the published studies of the soft tissue reaction to the hard tissue movements. They incorporate these data into prediction algorithms that can provide excellent single-line profile drawings predicting the final treatment goal. As mentioned for the manual techniques, also this method is relatively more acceptable to professionals, but again, it can only present the line drawing profile of the surgical simulation, which is of minor concern to the patient. Patient is often essentially interested in determining what he or she will look like after treatment (Proffit \& White, 1991; Sarver et al., 1988; Sarver \& Johnston, 1990; Turpin, 1995; Cunningham et al., 1991). 
The initial uses of computerized technology involved basic image modifications (Sarver et al., 1988) of both profile and frontal images obtained with a video camera, a digital camera, a scanner or a 35-mm slide scanner. Computer assisted cut-and-paste image modifications are useful to show significant facial changes expected after orthognatic surgery, however they do not provide the clinician the ability to determine the underlying hard tissue and intermaxillary dental relationship.

By the rapid improvement in computer technology and software systems, the integration of photographic images with cephalograms is enabled (Sarver \& Johnston, 1990; Turpin, 1990). Digital tracing can be accomplished either by direct digitization of the cephalogram or a previously traced image, or by indirect digitization of the image which is monitorized. The softwares superimpose the patients' profile photographs on the digitized cephalometric tracings and the computer-based estimation displays both line drawing tracings and the corresponding facial images (Fig.2). The main purposes of calibrating the cephalometric radiographs to the patient's digital photographs are relating the underlying hard tissue to the overlying soft tissue; allowing quantification of both hard and soft tissue movements and applying the algorithmic response ratios between them.

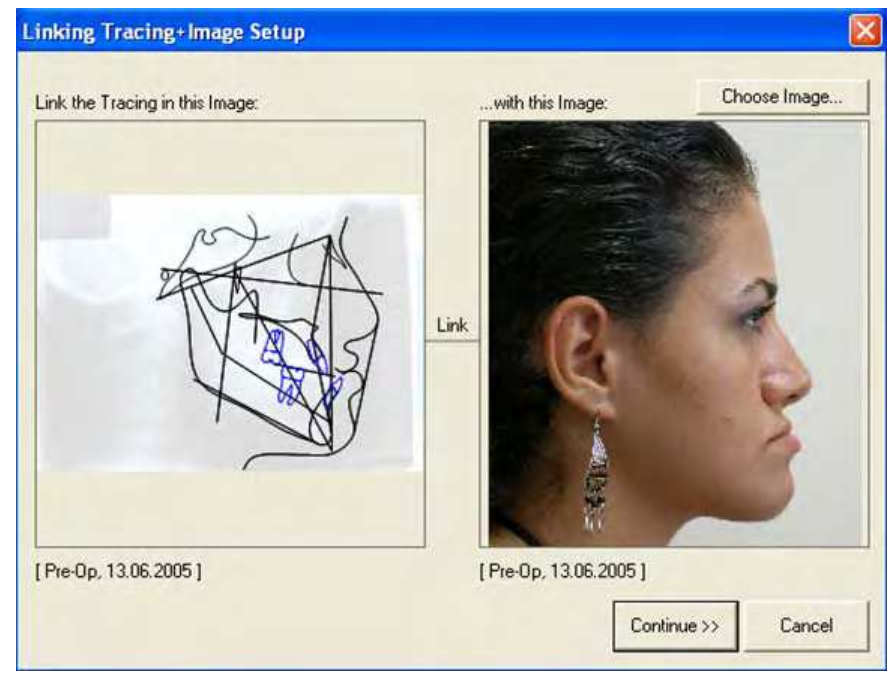

Figure 2. Screen view of linking the cephalogram with digital photograph of a patient

The Quick Ceph (Quick Ceph Systems, San Diego, CA) (Schendel et al.,1976), Dentofacial Planner (Dentofacial Software, Toronto, Canada) (Loh et al.,2001), Orthognathic Treatment Planner (Pacific Coast Software, Pacific Palisades, CA) (Jacobson \& Sarver, 2001), Prescription Portrait (Rx Data Inc) (Jacobson \& Sarver, 2001), Vistadent AT (GAC International) (Syliangco et al.,1997), Portrait Planner (Rx Data Inc., Ooltwah, Tenn), TIOPSTM (Total Interactive Orthodontics Planning System) and OPALTM (Orthognatic Prediction Analysis) are some of these softwares which were developed to allow the clinicians to manipulate the digital representations of hard and soft tissue profile tracings and subsequently process the preoperative image to simulate the treatment.

Studies on the accuracy of these computer-assisted predictions were started with Hing in 1989. In this study, the accuracy of Quick Ceph (Hing 1989) is evaluated on 16 mandibular 
advancement patients. The prediction tracings were produced from the preoperative cephalograms and then compared with the 1 year postoperative tracings. The results indicated that the horizontal landmark positions were overestimated and the vertical landmark positions were underestimated for the anterior mandible.

Kazandjian and colleagues compared the accuracy of two video imaging systems (Quick Ceph Image and Portrait Planner). Again, both programmes were noted to underestimate the amount of lower lip retraction and prediction was more superior than the actual result. Also the prediction errors in the vertical plane were grater than those in the sagittal plane (Smith et al., 2004; Kazandjian et al., 1999).

Smith and colleagues investigated perceived differences in the ability of current softwares to simulate the actual outcome of orthognathic surgery. They chose 10 difficult test cases with vertical discrepancies and "retreated" them using the actual surgical changes. Five programs - Dentofacial Planner Plus, Dolphin Imaging, Orthoplan, Quick Ceph Image, and Vistadent-were evaluated, by using both the default result and a refined result created with each program's enhancement tools. Three groups (orthodontists, oral-maxillofacial surgeons, and laypersons) judged the default images and the retouched simulations by ranking the simulations in side-by-side comparisons and by rating each simulation relative to the actual outcome on a 6-point scale. For the default and retouched images, Dentofacial Planner Plus was judged the best default simulation $79 \%$ and $59 \%$ of the time, respectively, and its default images received the best (lowest) mean score (2.46) on the 6-point scale. It also scored best (2.26) when the retouched images were compared, but the scores for Dolphin Imaging (2.83) and Quick Ceph (3.03) improved. Retouching had little impact on the scores for the other programs. However, the authors emphasize other considerations including the performance, ease of use, cost, compatibility, and image and practice management tools (Smith et al., 2004).

At present, a wide variety of computer-assisted cephalometric prediction softwares are available and Dolphin Imaging System (Dolphin Imaging, Canoga Park, CA) is one of these programs which is gaining popularity amongst surgeons and orthodontists. Dolphin Imaging Version 10.0 software, enables the indirect digitization of multiple dental, skeletal and soft-tissue landmarks of the scanned cephalogram with a cursor.

A group of patients who had received orthodontic treatment and underwent orthognathic surgery at Baskent University Adana Medical Teaching and Research Center during April 2003-April 2006, are studied to investigate the accuracy of Dolphin Imaging System software in predicting the soft tissue response subsequent to skeletal changes in a variety of orthognathic surgery cases. 11 patients (four males, seven females) with a mean age of 23.5 years (range 18-35 years) were included in the study and those who had adjunctive corrective procedures, such as genioplasty, rhinoplasty or liposuction, were excluded.

Case selection was made on the basis of the following inclusion criteria:

1. Availability of complete records, including lateral cephalometric radiographs and profile photographs, taken preoperatively, after orthodontic preparation, immediately before surgery and postoperatively at least 1 year after surgery.

2. Availability of lateral cephalograms allowing identification of selected hard and soft tissue cephalometric landmarks.

3. No history of cleft lip and/or palate.

4. No history of temporomandibular joint surgery. 
The preoperative and postoperative lateral cephalograms were obtained using a Planmeca PM 2002 EC Proline X-ray machine (Helsinki, Finland), with a dosing period of $0.4 \mathrm{~s}, 66 \mathrm{KV}$ and $12 \mathrm{~mA}$, using Kodak MXG General Purpose Green films (Colorado, USA). Only cephalograms displaying distinctive and clear anatomical landmarks were included for each patient. The registration and standardization of the preoperative and postoperative scans were accomplished with the patients registered to the cephalostat in the natural head position, looking at their own eyes in a mirror placed in front, at a certain distance, during the cephalometric imaging, providing a repeatable head position (Usumez \& Orhan 2001). Also, patients were asked to close their jaws in the centric occlusion, which also provided a repeatable registration regarding the mandibular position. A treatment plan was constituted for each patient, based on clinical and cephalometric evaluation and preoperative study models. All patients underwent one or a combination of the following surgical procedures:

1. Le Fort I maxillary impaction (three patients) or downfracture (three patients).

2. Le Fort I maxillary advancement (six patients).

3. Bilateral sagittal split osteotomy for mandibular advancement (three patients) or setback (six patients).

Again, all of them had been treated with pre- and postsurgical fixed orthodontic appliances, and the same method of fixation (plate and screw fixation) was used to stabilize the osteotomized segments, in either maxillary or mandibulary osteotomies. The surgical procedures with the demographic data of the patients are given in Table 1.

\begin{tabular}{|l|l|l|l|}
\hline & Patient & Age / Sex & \multicolumn{1}{|c|}{ Surgical procedure } \\
\hline 1 & S.B. & $26 / \mathrm{F}$ & $\begin{array}{l}\text { Maxillary advancement with downfracture; mandibular } \\
\text { setback }\end{array}$ \\
\hline 2 & D.Y. & $19 / \mathrm{F}$ & Mandibular setback \\
\hline 3 & H.V. & $20 / \mathrm{M}$ & Mandibular advancement \\
\hline 4 & S.I. & $35 / \mathrm{F}$ & $\begin{array}{l}\text { Maxillary advancement with impaction; mandibular } \\
\text { setback }\end{array}$ \\
\hline 5 & H.Y. & $26 / \mathrm{M}$ & Mandibular advancement \\
\hline 6 & H.E. & $25 / \mathrm{F}$ & Maxillary advancement with impaction \\
\hline 7 & S.O. & $18 / \mathrm{M}$ & $\begin{array}{l}\text { Maxillary advancement with impaction; mandibular } \\
\text { setback }\end{array}$ \\
\hline 8 & S.T. & $21 / \mathrm{F}$ & $\begin{array}{l}\text { Maxillary advancement with downfracture; mandibular } \\
\text { setback }\end{array}$ \\
\hline 9 & Z.S. & $25 / \mathrm{F}$ & Mandibular advancement \\
\hline 10 & C.H.U. & $19 / \mathrm{F}$ & Maxillary advancement with downfracture \\
\hline 11 & M.N. & $26 / \mathrm{M}$ & Mandibular setback \\
\hline
\end{tabular}

Table 1. Demographic data and type of surgical procedure

\section{Digital tracing}

The diagnostic records included the lateral cephalometric radiographs which were obtained immediately before surgery and at least 1 year after surgery, in order to eliminate the effect of soft tissue oedema (range 12-22 months). The preoperative and postoperative 
cephalometric radiographs were scanned using an Epson Expression 1680 Color Graphics Scanner (Epson, Long Beach, CA) into a digital format at $400 \mathrm{dpi}$, with a $100 \mathrm{~mm}$ calibration ruler, and displayed on a high-resolution monitor (Philips 107E61, NVIDIA Geforce4 MX4000, $1024 \times 768$ pixels). All the scanned images of the radiographs were then digitized, entered to a Pentium-based computer (Intel Pentium IV, $3.00 \mathrm{GHz}$, Windows XP Professional version 2002; Microsoft Corporation, Redmond, WA) and processed by one investigator (B.H.K.), using Dolphin Imaging Software version 10.0. To enable optimal landmark identification digitally, all tracings and digitations were performed in a darkened room. On the software, the digitization was started following the selection of the Ricketts and Steiner Analyses from the analysis toolbar. The landmarks were digitized as prompted by the Dolphin system directly on-screen, using a mouse-controlled cross-hair locator after locating two fiducial points placed $100 \mathrm{~mm}$ apart on the calibration ruler (Fig. 3).

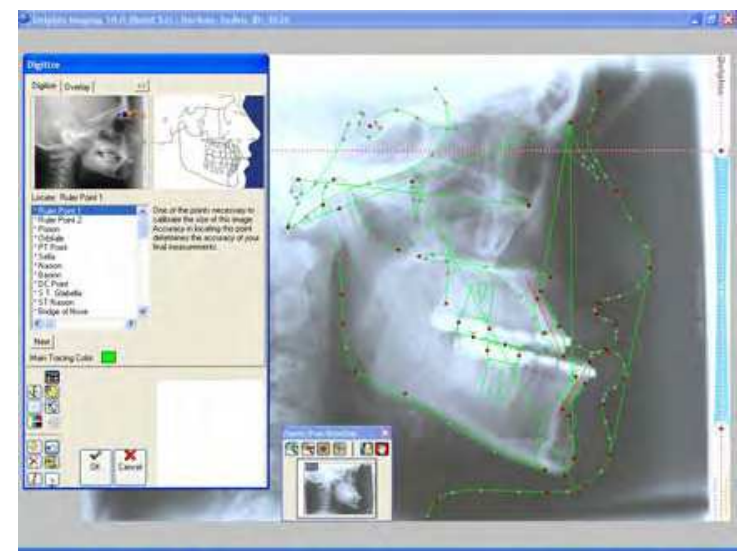

Figure 3. Screen view of the digitized cephalogram

Image enhancement tool functions involving blur/sharpen brightness and contrast options were used to assist in point identification when difficulty was encountered. Both preoperative and postoperative cephalograms were digitized and traced according to the selected analyses. In order to achieve the comparison of the actual postoperative outcome and the treatment simulation outcome from the software, preoperative and postoperative cephalogram tracings were first superimposed on the sella-nasion plane registered at sella. In order to enhance the superimposition accuracy, any structures and landmarks that have not moved during the surgical treatment, such as sella, nasion, basion, orbitale and porion, were simply transferred directly from the preoperative tracing to the postoperative cephalogram during the tracing session. Although the patients were registered according to the natural head position, any different positioning was corrected with a rotation option incorporated in the software. Hence, before transferring the stable points to the postoperative cephalogram, tracing of the preoperative cephalogram was overlaid, aligned and superimposed according to those anatomical points that had not moved during the surgery, such as sella, nasion, basion and orbitale, by using the rotation, enlarge or shrink options of the software. Preoperative and postoperative superimpositions were used to obtain a landmark movement spreadsheet indicating the exact amount of movement of each point after the surgical treatment. The location of any cephalometric landmark is expressed 
in terms of $x, y$ coordinates, according to a selected centre point which can be determined by the user. In this study, the point sella was determined as the centre.

Secondly, a treatment simulation was generated according to the data on this spreadsheet and prediction tracings were obtained using the postoperative actual displacement amounts. Finally, actual posttreatment tracings and prediction tracings were superimposed on the sella-nasion plane registered at sella. The differences between the actual postoperative tracings and the prediction tracings were measured on these superimpositions and the measurements in the horizontal and vertical planes were again obtained as a spreadsheet according to an $x, y$ coordinate system.

The facility of transferring the unchanged cranial structures during the surgical treatment to the posttreatment cephalogram, by overlaying the pretreatment tracing to the posttreatment cephalogram and displaying a millimetric landmark movement spreadsheet with respect to a $x, y$ coordinate system, which is operated by the 'Tracing differences analysis dialog' toolbar, are two newly-added features of Dolphin Imaging Software version 10.0 that provide further enhancement for the analysis in this latest version.

Comparisons between the predicted tracing and the actual profile for the soft tissue analysis were performed on seven cephalometric landmarks, including the tip of the nose, subnasale, soft tissue point A, upper lip, lower lip, soft tissue point B and soft tissue pogonion; the definitions for both cranial and soft tissue landmarks are shown in Figure 4. The preoperative profile view, computer assisted prediction and final postoperative profile view, with cephalometric tracings of four representative patients, are shown in Figures 5-8.

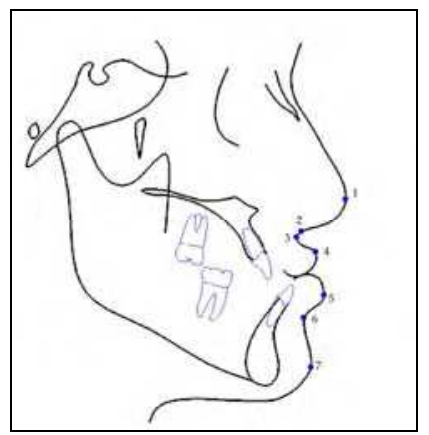

Figure 4. Cephalometric soft tissue landmarks and definitions used for analysis: 1 . Tip of nose, point of the anterior curve of the nose; 2 . Subnasale, point where the nose connects to the center of upper lip; 3 . Soft tissue A-point, most concave point between subnasale and the anterior point of the upper lip; 4 . Upper lip, most anterior point on the curve of the upper lip; 5. Lower lip, most anterior point on the curve of the lower lip; 6. Soft tissue B-point, most concave point between the lower lip and the soft tissue chin; 7. Soft tissue pogonion, point on the anterior curve of soft tissue chin

The differences in soft tissue outline between the predicted tracing and the actual profile achieved by surgery were evaluated mainly in the sagittal ( $x$ axis) and vertical ( $y$ axis) planes individually. The first analysis comprised the total group of patients and heterogeneous types of surgery, whereas the remaining analysis was performed with homogeneous groups, which were established based on the same type of surgery (maxillary advancement, mandibular setback or mandibular advancement). 
The results for the total study group and heterogeneous types of surgery are given in Table 2. Although the magnitude of mean differences are presented in the first analysis, the pattern and direction of the prediction errors with respect to the sagittal and vertical planes (overestimations or underestimations) are not included, as this would result in a methodological error in a heterogeneous group. According to Table 2, the mean differences between the prediction and actual final result were $<1 \mathrm{~mm}$ in four of seven soft tissue measurements, including the tip of nose, subnasale, soft tissue point A and soft tissue pogonion in the sagittal plane. In general, predictions were found to be more accurate for the sagittal plane than for the vertical plane.

\begin{tabular}{|l|l|l|}
\hline Cephalometric landmark & Sagittal Plane $(\mathbf{m m})$ & Vertical Plane $(\mathbf{m m})$ \\
\hline Tip of nose & $0.5 \pm 0.4$ & $1.4 \pm 1.3$ \\
\hline Subnasale & $0.9 \pm 0.7$ & $0.9 \pm 1.4$ \\
\hline Soft tissue A & $1.0 \pm 0.8$ & $1.3 \pm 1.1$ \\
\hline Upper lip & $1.5 \pm 1.4$ & $1.4 \pm 1.1$ \\
\hline Lower lip & $1.0 \pm 0.7$ & $2.5 \pm 1.7$ \\
\hline Soft tissue B & $0.6 \pm 0.5$ & $1.6 \pm 1.2$ \\
\hline Soft tissue pogonion & $0.7 \pm 0.5$ & $1.6 \pm 0.9$ \\
\hline
\end{tabular}

Table 2. Comparisons concerning total treatment group, regardless of the type of surgery. Values are given as mean (average of differences between the prediction and actual final result) \pm SD (standard deviation of differences between prediction and actual final result)

\begin{tabular}{|l|l|l|}
\hline Cephalometric landmark & Sagittal Plane $(\mathbf{m m})$ & Vertical Plane $(\mathbf{m m})$ \\
\hline Tip of nose & $-0.7 \pm 0.5$ & $-2.2 \pm 1.2$ \\
\hline Subnasale & $-1.4 \pm 0.4$ & $-1.6 \pm 1.7$ \\
\hline Soft tissue A & $-1.5 \pm 0.6$ & $-1.9 \pm 1.2$ \\
\hline Upper lip & $+2.0 \pm 1.5$ & $+1.8 \pm 1.2$ \\
\hline
\end{tabular}

Table 3. Differences for maxillary advancement in 6 patients

\begin{tabular}{|l|l|l|}
\hline Cephalometric landmark & Sagittal Plane $(\mathbf{m m})$ & Vertical Plane $(\mathbf{m m})$ \\
\hline Lower lip & $+1.1 \pm 0.8$ & $-2.0 \pm 2.1$ \\
\hline Soft tissue B & $-0.6 \pm 0.5$ & $-1.9 \pm 1.3$ \\
\hline Soft tissue pogonion & $-0.7 \pm 0.5$ & $-2.0 \pm 1.1$ \\
\hline
\end{tabular}

Table 4. Differences for mandibular setback in 6 patients

\begin{tabular}{|l|l|l|}
\hline Cephalometric landmark & Sagittal Plane $(\mathbf{m m})$ & Vertical Plane $(\mathbf{m m})$ \\
\hline Lower lip & $+0.6 \pm 0.3$ & $-3.1 \pm 1.3$ \\
\hline Soft tissue B & $-0.7 \pm 0.4$ & $+0.6 \pm 0.4$ \\
\hline Soft tissue pogonion & $+0.7 \pm 0.7$ & $-1.2 \pm 0.3$ \\
\hline
\end{tabular}

Table 5. Differences for mandibular advancement in 3 patients 
Tables 3, 4 and 5 present the evaluations for unique types of surgeries, including maxillary advancement, mandibular setback and mandibular advancement, respectively. These comparisons also include the pattern and direction of the prediction errors with respect to the sagittal and vertical planes (overestimations or underestimations). The $(+)$ values present the overestimations (predicted landmarks were anterior or inferior with respect to actual result), whereas the $(-)$ values present the underestimations (predicted landmarks were posterior or superior with respect to actual result) of the predictions.

The analysis of Table 3 provides data for the maxillary advancements. In general, the computer generated predictions tended to underestimate the differences for the tip of nose, subnasale and soft tissue point A, whereas the upper lip was predicted to be more protrusive and inferiorly positioned with respect to the actual outcome in both sagittal and vertical planes.

\begin{tabular}{|l|c|c|c|c|c|c|}
\hline & \multicolumn{3}{|c|}{ Sagittal plane; x-axis (\%) } & \multicolumn{3}{c|}{ Vertical plane; y-axis (\%) } \\
\hline & $<\mathbf{1 ~} \mathbf{~ m m}$ & $\mathbf{1 - 2} \mathbf{~ m m}$ & $\mathbf{>} \mathbf{~ m m}$ & $<\mathbf{~} \mathbf{~ m m}$ & $\mathbf{1 - 2} \mathbf{~ m m}$ & $>\mathbf{2} \mathbf{~ m m}$ \\
\hline Tip of nose & 82 & 18 & - & 46 & 27 & 27 \\
\hline Subnasale & 45 & 55 & - & 82 & - & 18 \\
\hline Soft tissue A & 46 & 36 & 18 & 55 & 27 & 18 \\
\hline Upper lip & 55 & 18 & 27 & 36 & 36 & 28 \\
\hline Lower lip & 55 & 27 & 18 & 18 & 27 & 55 \\
\hline Soft tissue B & 73 & 27 & - & 36 & 18 & 46 \\
\hline Soft tissue pogonion & 73 & 27 & - & 9 & 64 & 27 \\
\hline Overall & $\mathbf{6 1}$ & $\mathbf{3 0}$ & $\mathbf{9}$ & $\mathbf{4 0}$ & $\mathbf{2 8}$ & $\mathbf{3 2}$ \\
\hline
\end{tabular}

Table 6. Frequency of predicted errors. Predicted errors are shown as 3 groups; error $<1 \mathrm{~mm}$, error between $1-2 \mathrm{~mm}$, and error $>2 \mathrm{~mm}$. Overall value is the average of all predicted errors

Comparisons regarding the mandibular setback surgeries are given in Table 4; the computer-generated predictions in the sagittal plane were closer to the actual surgical results than those in the vertical plane. Table 5 shows comparisons between the computer based predictions and the actual results in the mandibular advancement group. The predictions in the vertical plane were found to be less accurate than those in the sagittal plane. The distribution of frequencies of computer-based prediction errors are given in Table 6 and the results are quantified in three groups as errors $<1 \mathrm{~mm}, 1-2 \mathrm{~mm}$ and $>2 \mathrm{~mm}$. In general, the prediction errors in the sagittal plane were smaller than those reported for the vertical plane. None of the prediction errors was greater than $2 \mathrm{~mm}$ for the tip of the nose, subnasale, soft tissue point B point and soft tissue pogonion in the sagittal plane. The majority of errors for the tip of the nose was $<1 \mathrm{~mm}$ in the sagittal plane. The distribution of prediction errors present a wider range in the vertical plane; the analysis of all landmarks exhibits prediction errors $>2 \mathrm{~mm}$, whereas subnasale has a relatively high accuracy, with $82 \%$ of the errors $<1 \mathrm{~mm}$.

In general, the results of this study reveal that the computer-based predictions were more accurate in the sagittal plane than those observed in the vertical plane for all predetermined soft tissue landmarks. The frequency of prediction errors $<2 \mathrm{~mm}$ is $91 \%$ for the sagittal plane, whereas $68 \%$ of the prediction errors were $<2 \mathrm{~mm}$ for the vertical plane. These results 
were proved to be satisfactory, as errors of 1-2 mm were previously reported to be clinically acceptable by orthodontists, surgeons and lay people (Kazandjian et al., 1999). The literature review also reveals a number of studies using former versions of Dolphin Imaging software. A recent study by Gossett et al. (Gossett et al., 2005), in which the prediction accuracy of computer assisted surgical VTOs is compared with conventional VTOs, revealed a statistical significant difference of only 1 in angular and 2 in linear measurements, including the interincisal angle, upper incisor to nasion-A line and lower incisor to nasion-B line, respectively. They used Dolphin Imaging System version 8.0 for image analysis, but this study differs by their method of excluding soft tissue predictions, as the early postoperative radiographs were thought to be prone to errors due to postoperative soft tissue oedema. They concluded that this system was comparable to conventional VTO in its prediction accuracy. However, conventional VTO was found to be relatively more reliable for predictions of the mandibular arch when compared with the Dolphin Imaging System.
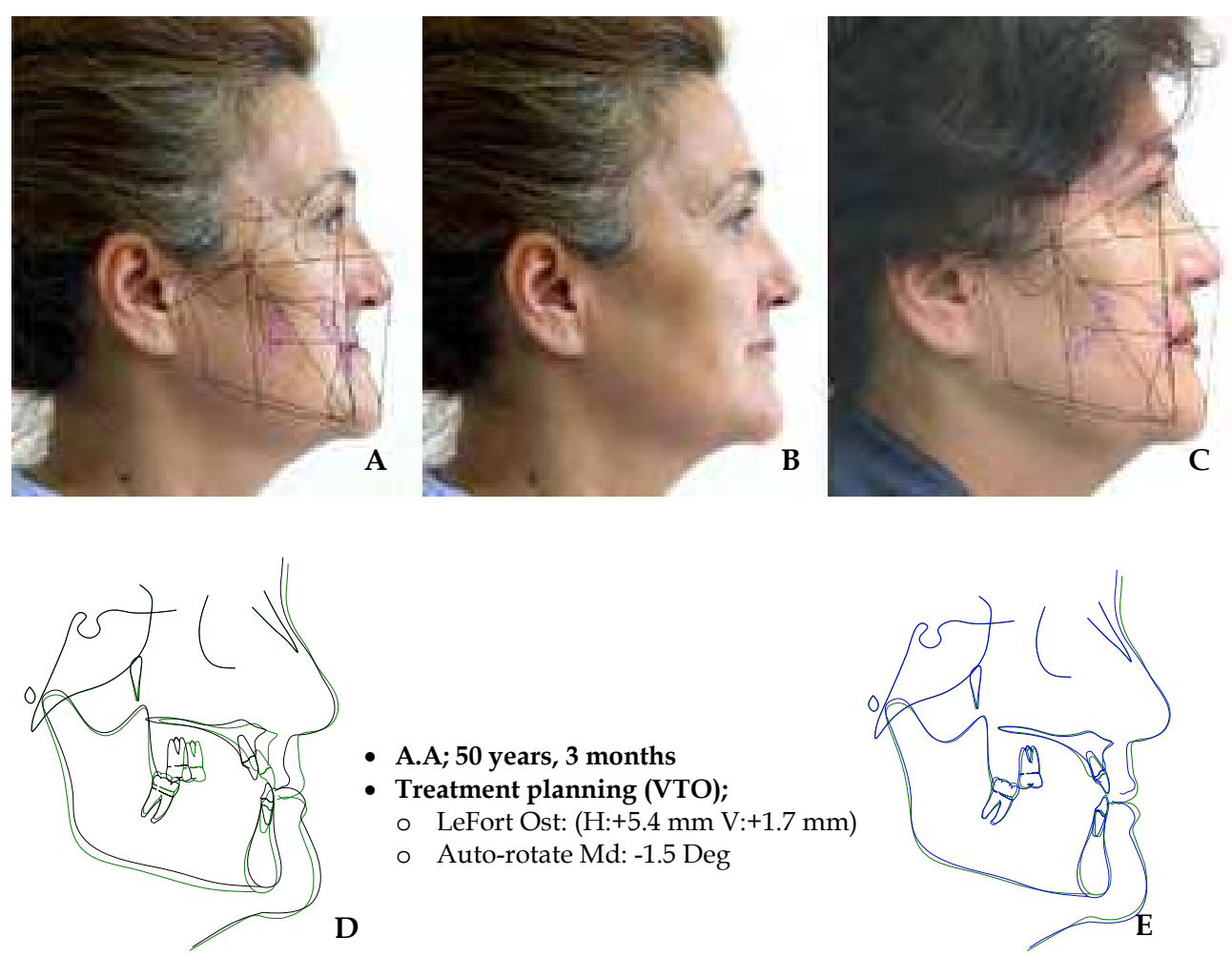

H: Horizontal movement; V: Vertical movement; Md: Mandible.

Figure 5. The preoperative profile view (A), computer assisted prediction (B) and final postoperative profile view (C), initial (black) and final (green) cephalometric tracings superimposition (D), predicted (blue) and final (green) cephalometric tracings superimposition $(\mathrm{E})$ 

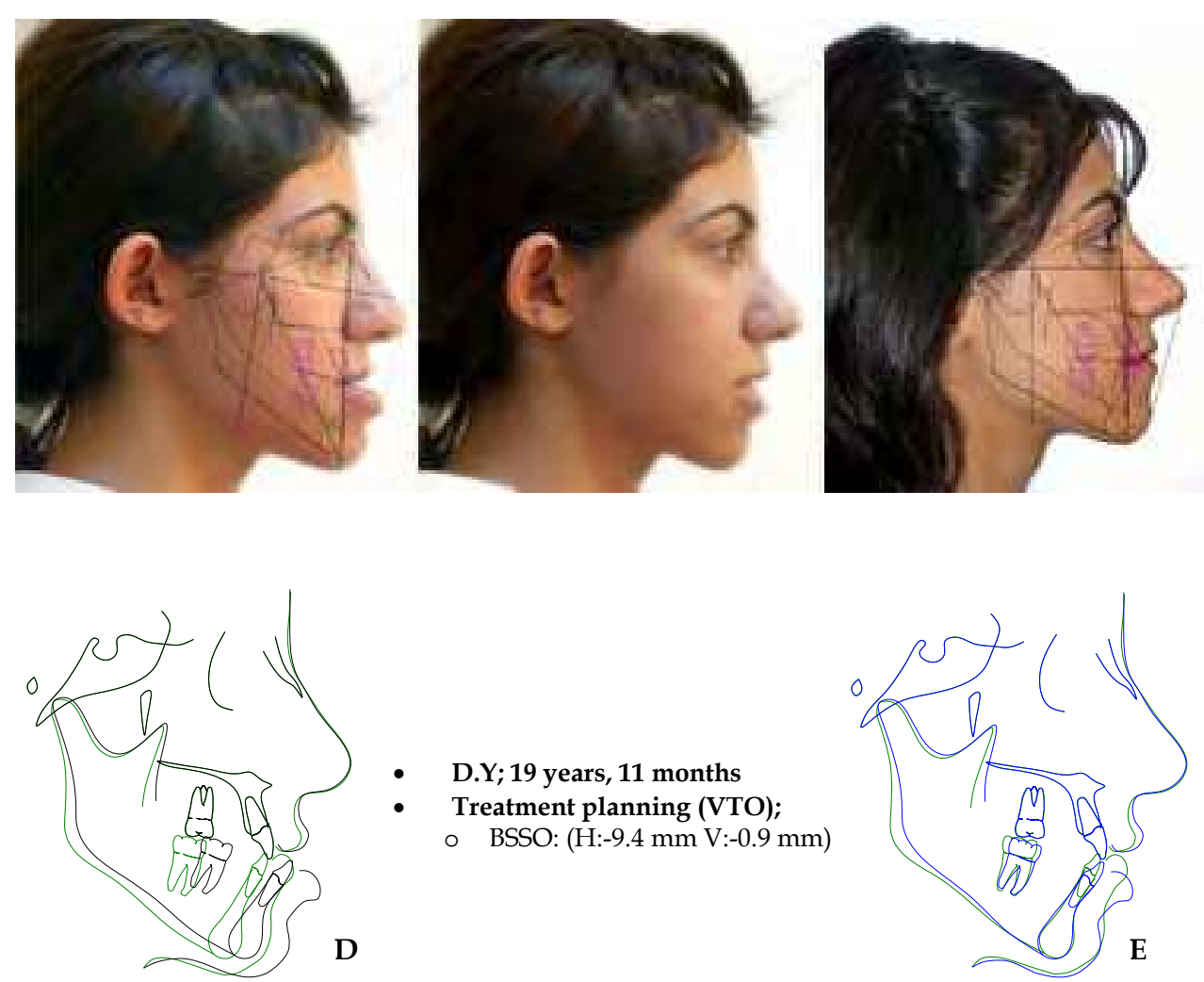

- D.Y; 19 years, 11 months

- Treatment planning (VTO);

○ BSSO: (H:-9.4 mm V:-0.9 mm)

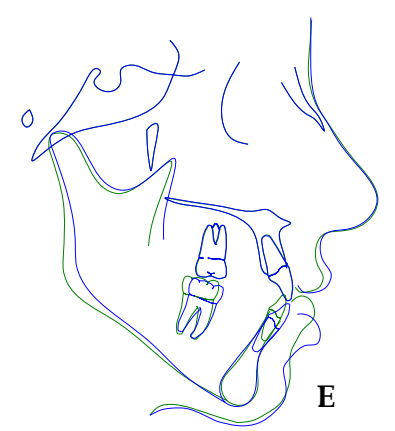

H: Horizontal movement; V: Vertical movement; BSSO: Bilateral sagittal split osteotomy.

Figure 6. The preoperative profile view (A), computer assisted prediction (B) and final postoperative profile view (C), initial (black) and final (green) cephalometric tracings superimposition (D), predicted (blue) and final (green) cephalometric tracings superimposition $(\mathrm{E})$

In another study, Lu et al. (Lu et al., 2003) also used the Dolphin Imaging System version 8.0 to predict soft tissue outcomes after orthognathic surgery on patients who underwent simultaneous maxillary and mandibular setback operations. The results showed a disagreement with our study, in that the software predictions of surgical profile changes were more accurate in the vertical plane than in the sagittal plane. Predictions directed to tip of the nose and subnasale revealed these sites as the most reliable ones that the software could predict, whereas the least accurate predicted landmark was the lower lip, measured in the sagittal plane. These results display an agreement with our results for the tip of the nose; however, unlike Lu et al. (Lu et al., 2003), the prediction for the upper lip in the sagittal plane and for the lower lip in the vertical plane were reported as the least accurate landmarks in the presented study.

A considerable number of studies carried out with various prediction imaging programs reveals a consensus towards the variability in lower lip predictions (Sinclair et al., 1995; Eales et al., 1994; Konstiantos et al., 1994; Kolokitha et al. 1996; Schultes et al., 1998; Csaszar 
et al., 1999). The influence of incisor position and angulation, soft tissue thickness and tonicity, perioral musculature and muscle attachments were considered as possible explanations for the low accuracy rates for lower lip predictions (Syliangco et al., 1997; Stella et al. 1989). When compared with previous studies (Syliangco et al., 1997; Hing, 1989), we observed that the accuracy of lower lip prediction was high in the sagittal plane, whereas the vertical plane measurements revealed greater prediction errors for mandibular advancement surgeries. In this context, Dolphin Imaging offers the 'auto lip adjustment feature', which enables the user to adjust both lips simultaneously in the vertical and horizontal planes (Fig.9).
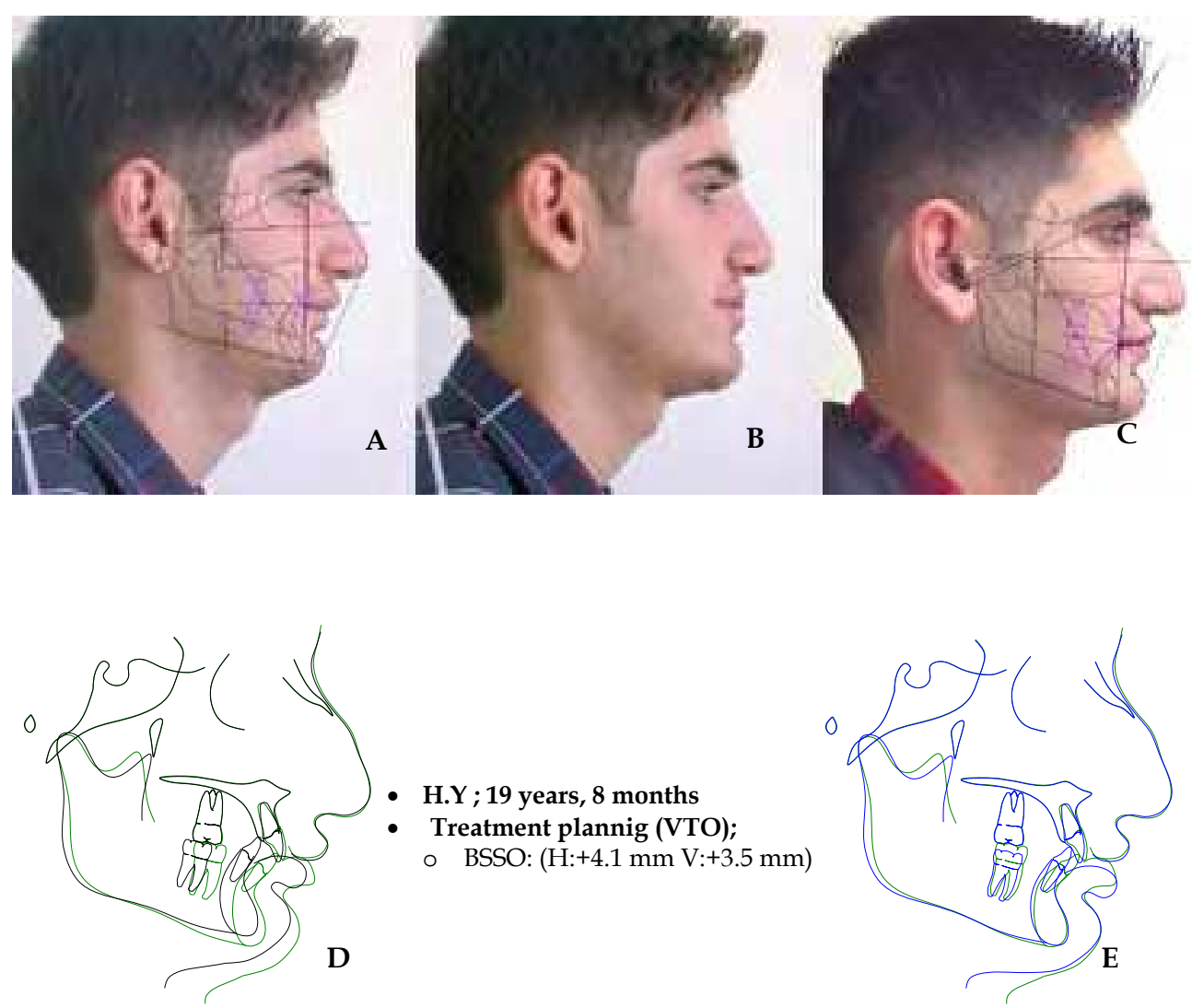

H: Horizontal movement; V: Vertical movement; BSSO: Bilateral sagittal split osteotomy.

Figure 7. The preoperative profile view (A), computer assisted prediction (B) and final postoperative profile view (C), initial (black) and final (green) cephalometric tracings superimposition (D), predicted (blue) and final (green) cephalometric tracings superimposition (E) 

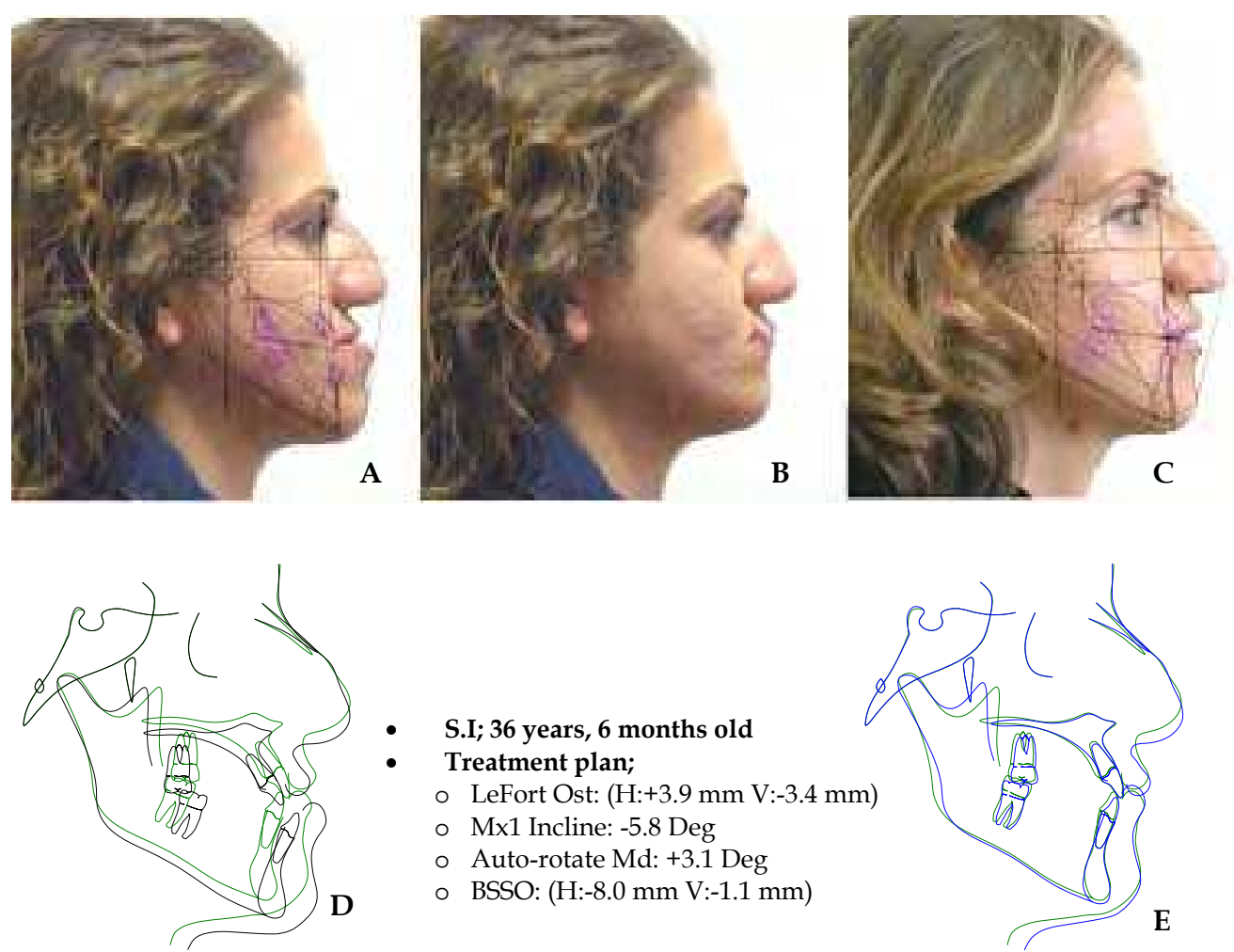

- $\quad$ S.I; 36 years, 6 months old

- Treatment plan;

○ LeFort Ost: (H:+3.9 mm V:-3.4 mm)

○ Mx1 Incline: -5.8 Deg

- Auto-rotate Md: +3.1 Deg

○ BSSO: (H:-8.0 mm V:-1.1 mm)

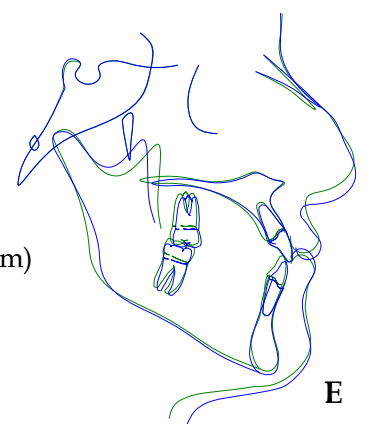

H: Horizontal movement; V: Vertical movement; Mx1:Maxillary incisor; Md:Mandible; BSSO: Bilateral sagittal split osteotomy.

Figure 8. The preoperative profile view (A), computer assisted prediction (B) and final postoperative profile view (C), initial (black) and final (green) cephalometric tracings superimposition (D), predicted (blue) and final (green) cephalometric tracings superimposition $(\mathrm{E})$

The favourable effects of visualized treatment objectives on patients' perception have led to computer-assisted cephalometric predictions being an integral part of orthognathic surgery treatment planning. However, besides many advantages of these systems, it should be kept in mind that the presentation of these predictions to patients should be done carefully, to avoid unrealistic expectations of the surgical outcome, as some authors have some concerns about predictions might imply a guaranteed outcome (Pospisil, 1987). Philips et al. (Philips et al., 1995) reported higher self-image expectation for patients for whom the video-image case presentation was performed when compared with a standard case presentation group. However, Sarver et al. (Sarver et al.1988) have found that $89 \%$ of a sample of patients judged video images to be realistic and $83 \%$ of the patients benefited from image analysis in determining whether to undergo the operation.

Although we have attempted to provide standardized material for this current study, with the precautions described and with the facilities of a newer version of the software, it may 
still be prone to some errors due to individual intersubject variations; differences in the exact time period from preoperative to postoperative imaging for each case, or soft tissue profile changes due to effects other than surgery (weight gain or weight loss), variations in the image quality or prediction algorithms may be considered as the possible sources of errors.
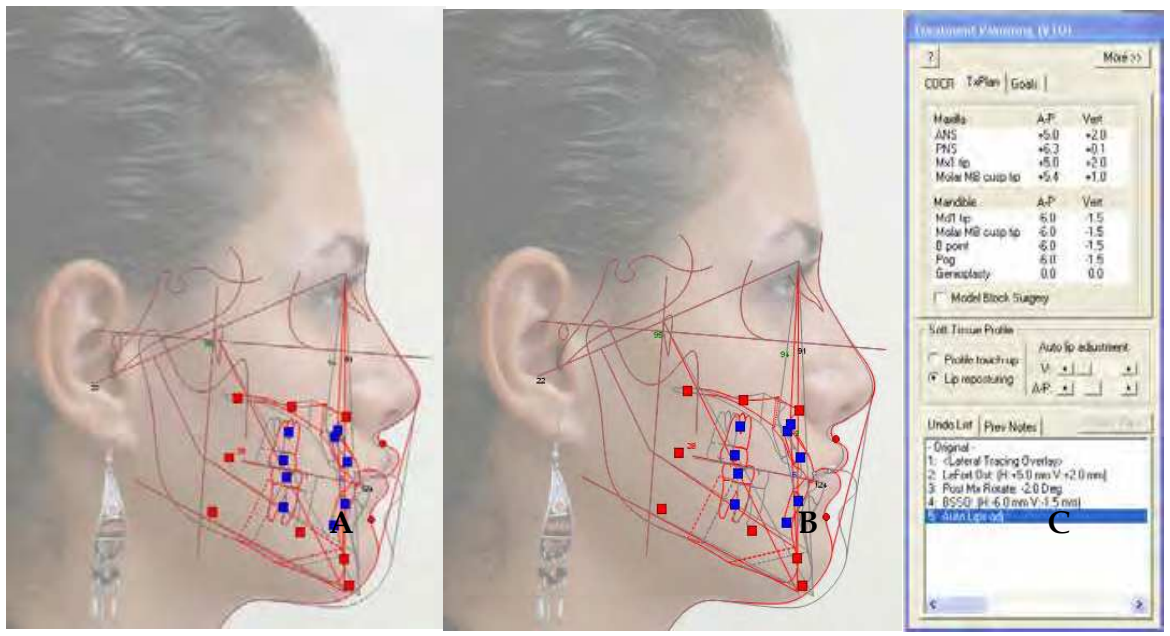

Figure 9. A computer assisted visual treatment planning (VTO). Unrealistic upper lip projection (A) , the computer assisted visual treatment planning with lip adjustment. Note the upper lip correction (B), and treatment planning window of the software (C)

The progression in computer science is a rapid and ongoing process. Novel techniques use three-dimensional colour photographs, algorithms and reconstructed 3D CT scans to enhance the prediction accuracies of these systems (Xia et al., 2000). Holberg et al. compared 3D prediction based on finite element method with a two-dimensional prediction programe (Dentofacial Planner Plus ${ }^{\mathrm{TM}}$ ) and found the prediction accuracy to be satisfactory. In addition to profile prediction, they reported that the procedure allowed a differentiated 3D assessment of esthetically important regions such as cheeks, nasolabial folds and the nasal wings without an additional x-ray radiation (Holberg et al., 2005).

Further investigations are also required to incorporate individual patient variability in order to integrate these systems to our current use.

\section{References}

Burstone C, James RB, Legan H, Murphy GA, Norton LA. (1978). Cephalometrics for orthognathic surgery. J Oral Surg , 36, 4, 269-277, 0022-3255.

Csaszar GR, Bruker-Csaszar B, Niederdellmann H. (1999). Prediction of soft tissue profiles in orthodontic surgery with the Dentofacial Planner. Int J Adult Orthod Orthognath Surg, 14, 4, 285-290, 0742-1931.

Cunningham SJ, Hunt NP, Feinmann C. (1995). Psychological aspects of orthognathic surgery: a review of literature. Int JAdult Orthod Orthognath Surg, 10, 3, 159-177, 0742-1931. 
Eales EA, Newton C, Jones ML, Sugar A. (1994). The accuracy of computerized prediction of the soft tissue profile: a study of 25 patients treated by means of the Le Fort I osteotomy. Int J Adult Orthod Orthognath Surg, 9, 2, 141-152, 0742-1931.

Gossett CB,Preston CB, Dunford R, Lampasso J. (2005). Prediction accuracy of computerassisted surgical visual treatment objectives as compared with conventional visual treatment objectives. J Oral Maxillofac Surg, 63, 5, 609-617, 0301-0503.

Harradine NW, Birnie DJ. (1985). Computerized prediction of the results of orthognathic surgery. J Maxillofac Surg, 13, 6, 245-249, 0301-0503.

Hing NR. (1989). The accuracy of computer generated prediction tracings. Int J Oral Maxillofac Surg, 18, 3, 148-51, 0901-5027.

Holberg C, Heine AK, Geis P, Schwenzer K, Rudzki-Janson I. (2005). Three-dimensional soft tissue prediction using finite elements. Part II: Clinical application. J Orofac Orthop, $66,2,122-134,1434-5293$.

Jacobson R, Sarver DM. (2001). The predictability of maxillary repositioning in Le Fort I orthognathic surgery. Am J Orthod Dentofacial Orthop, 122, 2, 142-154, 0889-5406.

Kazandjian S, Sameshima GT, Champlin T, Sinclair PM. (1999). Accuracy of video imaging for predicting the soft tissue profile after mandibular set-back surgery. Am J Orthod Dentofacial Orthop, 115, 4, 382-389, 0889-5406.

Kolokitha OE, Athanasiou AE, Tuncay OC. (1996). Validity of computerized predictions of dentoskeletal and soft tissue profile changes after mandibular setback and maxillary impaction osteotomies. Int J Adult Orthod Orthognath Surg, 11, 2, 137-154, 0742-1931.

Konstiantos KA, O'Reilly MT, Close J. (1994). The validity of the prediction of soft tissue profile changes after Le Fort I osteotomy using the Dentofacial Planner. Am J Orthod Dentofacial Orthop, 105, 3, 241-249, 0889-5406.

Loh S, Heng JK, Ward-Booth P, Winchester L, McDonald F. (2001).A radiographic analysis of computer prediction in conjunction with orthognathic surgery. Int J Oral Maxillofac Surg, 30, 4, 259-263, 0901-5027.

Lu CH, Ko EWC, Huang CS. (2003). The accuracy of video imaging prediction in soft tissue outcome after bimaxillary orthognathic surgery. J Oral Maxillofac Surg, 61, 3, 333342, 0301-0503.

Nattrass C, Sandy JR. (1995). Adult orthodontics. Br J Orthod, 22, 4, 331-337, 0301-228X.

Phillips C, Hill BJ, Cannac C. The influence of video imaging on patients' perceptions and expectations. (1995). Angle Orthod, 65, 4, 263-270, 0003-3219.

Pospisil OA. (1987). Reliability and feasibility of prediction tracing in orthognathic surgery. J Craniomaxillofac Surg, 15, 2, 79-83, 1010-5182.

Proffit WR, White RP. (1991). The need for surgical orthodontic treatment, In: Surgical Orthodontic Treatment, Proffit WR, White RP Jr, 2-24, Mosby-Year Book, St Louis, $\mathrm{MO}$, USA.

Proffit WR, Sarver DM. (2003). Treatment Planning: Optimizing Benefit to the Patient, In: Contemporary Treatment of Dentofacial Deformity, Proffit WR, White RP Jr, Sarver DM, 172-244, Mosby-Year Book, 0-323-01697-9, St Louis, MO, USA.

Sarver DM, Johnston MW, Maturas VJ. (1988). Video imaging for planning and counseling in ortho surgery. J Oral Maxfac Surg, 46, 1, 939-945, 0301-0503. 
Sarver DM, Johnston MW. (1990).Video-imaging: techniques for superimposition of cephalometric radiography and profile images. Int J Adult Orthod Orthognath Surg, 5, 4, 241-248, 0742-1931.

Sarver DM (2000). The Application of Video Imaging Technology to Orthognatic Surgery, In: Oral and Maxillofacial Surgery, Fonseca JR, 57-81, W.B. Saunders Comp., 0-72169633-3, Philadelphia, USA.

Schendel SA, Eisenfeld J, Bell WH, Epker BN. (1976). Superior repositioning of the maxilla. Stability and soft tissue osseous relations. Am J Orthod, 70, 6, 663-674, 0889-5406.

Schultes G, Gaggl A, Karcher H. (1998). Accuracy of cephalometric and video-imaging program Dentofacial Planner Plus in orthognathic surgical planning. Comput Aided Surg, 3, 3, 108-114, 1092-9088.

Sinclair PM, Kilpelainen P, White R, Rogers L, Sarver D. (1995). The accuracy of videoimaging in orthognathic surgery. Am J Orthod Dentofacial Orthop, 107, 2, 177-185, 0889-5406.

Smith JD, Thomas PM, Proffit WR. (2004). A comparison of current prediction imaging programs. Am J Orthod Dentofacial Orthop, 125, 5, 527-536, 0889-5406.

Stella JP, Streater MR, Epker BN, Sinn DP. (1989). Predictability of upper soft tissue changes with maxillary advancement. J Oral Maxillofac Surg, 47, 7, 697-703, 0301-0503.

Syliangco ST, Sameshima GT, Kaminishi RM, Sinclair PM. (1997). Predicting soft tissue changes in mandibular advancement surgery: a comparison of two video-imaging systems. Angle Orthodont, 67, 5, 337-346, 0003-3219.

Turpin DL. (1990). Computers coming on line for diagnosis and treatment planning. Angle Orthod, 60, 3, 163-164, 0003-3219.

Turpin DL. (1995). The need for video imaging. Angle Orthod, 65, 4, 243-244, 0003-3219.

Usumez S, Orhan M. (2001). Inclinometer method for recording and transferring natural head position in cephalometrics. Am J Orthod Dentofacial Orthop, 120, 6, 664-670, 0889-5406.

Walters H, Walters DH. (1986). Computerized planning of maxillofacial osteotomies: The program and its clinical application. Br J Oral Maxillofac Surg, 24, 3, 178-189, 02664356.

Xia J, SammanN, UeungRW, et al. (2000). Computer-assisted threedimensional surgical planning and simulation. 3D soft tissue planning and prediction. Int J Oral Maxillofac Surg, 29, 4, 250-258, 0901-5027. 


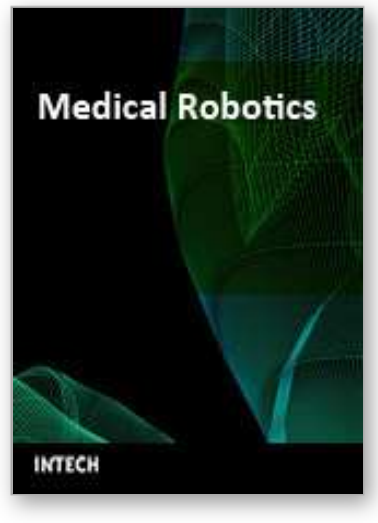

\author{
Medical Robotics \\ Edited by Vanja Bozovic
}

ISBN 978-3-902613-18-9

Hard cover, 526 pages

Publisher I-Tech Education and Publishing

Published online 01, January, 2008

Published in print edition January, 2008

The first generation of surgical robots are already being installed in a number of operating rooms around the world. Robotics is being introduced to medicine because it allows for unprecedented control and precision of surgical instruments in minimally invasive procedures. So far, robots have been used to position an endoscope, perform gallbladder surgery and correct gastroesophogeal reflux and heartburn. The ultimate goal of the robotic surgery field is to design a robot that can be used to perform closed-chest, beating-heart surgery. The use of robotics in surgery will expand over the next decades without any doubt. Minimally Invasive Surgery (MIS) is a revolutionary approach in surgery. In MIS, the operation is performed with instruments and viewing equipment inserted into the body through small incisions created by the surgeon, in contrast to open surgery with large incisions. This minimizes surgical trauma and damage to healthy tissue, resulting in shorter patient recovery time. The aim of this book is to provide an overview of the state-of-art, to present new ideas, original results and practical experiences in this expanding area. Nevertheless, many chapters in the book concern advanced research on this growing area. The book provides critical analysis of clinical trials, assessment of the benefits and risks of the application of these technologies. This book is certainly a small sample of the research activity on Medical Robotics going on around the globe as you read it, but it surely covers a good deal of what has been done in the field recently, and as such it works as a valuable source for researchers interested in the involved subjects, whether they are currently "medical roboticists" or not.

\title{
How to reference
}

In order to correctly reference this scholarly work, feel free to copy and paste the following:

Zafer Ozgur Pektas, Beyza Hancioglu Kircelli and Ulkem Cilasun (2008). The Use of Software Systems for Visualized Treatment Objectives in Orthognatic Surgery, Medical Robotics, Vanja Bozovic (Ed.), ISBN: 978-3902613-18-9, InTech, Available from:

http://www.intechopen.com/books/medical_robotics/the_use_of_software_systems_for_visualized_treatment_ objectives_in_orthognatic_surgery

\section{INTECH}

open science | open minds

\author{
InTech Europe \\ University Campus STeP Ri \\ Slavka Krautzeka 83/A
}

\author{
InTech China \\ Unit 405, Office Block, Hotel Equatorial Shanghai \\ No.65, Yan An Road (West), Shanghai, 200040, China
}


51000 Rijeka, Croatia

Phone: +385 (51) 770447

Fax: +385 (51) 686166

www.intechopen.com
中国上海市延安西路65号上海国际贵都大饭店办公楼 405 单元 Phone: +86-21-62489820

Fax: +86-21-62489821 
(C) 2008 The Author(s). Licensee IntechOpen. This chapter is distributed under the terms of the Creative Commons Attribution-NonCommercialShareAlike-3.0 License, which permits use, distribution and reproduction for non-commercial purposes, provided the original is properly cited and derivative works building on this content are distributed under the same license. 